\title{
Percepções dos indivíduos sobre as consequências do teletrabalho na configuração home-office: estudo de caso na Shell Brasil
}

\section{Individuals' perceptions about the consequences of telework in the home-office configuration: a case study at Shell Brazil}

\author{
Alexandre Moço Barros ${ }^{1}$ \\ José Roberto Gomes da Silva ${ }^{2}$
}

\begin{abstract}
Resumo
Com o avanço da tecnologia da informação e da comunicação e as mudanças da sociedade, novas formas de flexibilização das relações de trabalho têm se disseminado, entre as quais o teletrabalho. Uma das modalidades de teletrabalho é aquela em que o indivíduo executa as tarefas de casa, mantendo, porém, o vínculo de emprego formal com uma organização. Este artigo focaliza, em especial, essa modalidade, levantando as percepções dos indivíduos que nela atuam sobre as consequências para a sua vida pessoal e profissional. Trata-se de estudo de caso na Shell Brasil, empresa que, desde 2000, promoveu a migração de alguns funcionários para o regime home-office. A metodologia de natureza qualitativa compreendeu entrevistas com profissionais desse grupo. Os resultados permitiram identificar um quadro conceitual que aponta elementos condicionantes e elementos que os indivíduos parecem utilizar como balizadores de suas avaliações sobre a condição de teletrabalhadores home-office. Entre os condicionantes, destacamse características da pessoa, da organização, dos recursos e procedimentos disponibilizados, do trabalho, da família, do espaço doméstico e da sociedade. Como elementos balizadores surgem: o desempenho na empresa e os efeitos para a carreira, a relação com o trabalho, a vida pessoal e as relações sociais e em família.
\end{abstract}

Palavras-chave: teletrabalho; home-office; relações de trabalho; tempo e espaço; gestão de RH.

\begin{abstract}
With the advance of the information and communication technology and the recent changes in society, new forms of work relations have become popular, including telework. An example of telework arrangement is that in which the individual performs tasks from home, maintaining, however, a formal employment with an organization. This article focuses on such modality, aiming to identify individuals' perceptions about the consequences of telework for their personal and professional lives. The article presents a qualitative case study conducted at Shell Brazil, a company that has transferred some employees to the home-office scheme since the year of 2000. The methodology is comprised of interviews with individuals in that group. Results helped to identify a conceptual framework pointing to constraint and reference aspects that they use to evaluate their situation as home-office employees. Among the constraints, some aspects concern to: the individual, the organization, the resources available, the work tasks, the family, the home space and the characteristics of society. As reference elements, we can observe: the impacts on performance and the effects on career; the individual's relation with work; the quality of personal life and the relations in family and in society.
\end{abstract}

Key words: telework; home-office; work relations; time and space; HR management.

1 Mestre em Administração de Empresas pela Escola IAG/PUC-Rio. Business Development Coordinator - Shell Brasil Ltda Endereço: Rua Joaquim Floriano, $10521^{\circ}$ andar, São Paulo-SP - São Paulo/SP - Brasil - CEP: 04534-014. E-mail: alexandre.m.barros247@gmail.com

2 In memoriam: Doutor em Administração de Empresas pela Pontifícia Universidade Católica do Rio de Janeiro. Professor da Pontifícia Católica do Rio de Janeiro - PUC/IAG. Endereço: PUC/IAG - Rua Marquês de São Vicente, 225 - Rio de Janeiro/RJ - Brasil. CEP: 22453-900 .Marquês de São Vicente, 225 Gávea, Rio de Janeiro - RJ - Brasil - CEP:22451-900

Artigo submetido em novembro de 2008 e aceito em março de 2009 


\section{Introdução}

Uma das marcas do final do século XX foi, segundo Kumar (1997), o surgimento de um tipo de discurso que anunciava a transformação das bases da modernidade e a emergência de um novo modelo de sociedade, ao qual se atribuíram diferentes nomeações, tais como "sociedade pós-industrial", "sociedade pós-moderna" e "sociedade da informação". Na voz de autores como Alvin Tofler e Daniel Bell, preconizava-se uma nova lógica de interação humana, na medida em que o avanço da globalização e o acelerado desenvolvimento da tecnologia da informação e da comunicação (TIC) rompiam as fronteiras espaço-temporais estabelecidas pela modernidade. Kumar ressalta, porém, a natureza utópica desse discurso. Em termos da sociedade, ele tendia a ser apresentado como uma espécie de estágio evoluído do projeto da modernidade, sinalizando a tão almejada universalização dos benefícios do progresso. Em termos das organizações, a suposta ruptura de fronteiras representaria a possibilidades de expansão para além dos muros das fábricas, das barreiras aduaneiras e dos limites contratuais de trabalho. Para os indivíduos, desenhava-se um sentido ampliado de cidadania, com um grau de flexibilização da vida cotidiana e de integração social jamais imaginado. Ao mesmo tempo, observa Kumar, em contraponto a essa visão positiva, surgiram discursos críticos que viam nessas transformações uma espécie de vitória final do capitalismo, cujas consequências para a sociedade e para os indivíduos estariam longe de serem ideais.

Quanto às implicações para as relações de trabalho, na visão de autores como Boltanski e Chiapello (1999) e Capelli (1999), essa dualidade de percepções sobre os rumos da modernidade tardia é resultante das ambiguidades de um discurso que aponta mudanças, mas que não dá conta das várias inconsistências que delas resultam. As últimas décadas trouxeram inúmeros processos de reestruturação das organizações e uma intensa reconfiguração das relações de trabalho, mas pouco ainda se conhece acerca das consequências dessas mudanças.

Um exemplo de fenômeno sobre cujas implicações ainda há uma significativa lacuna de conhecimentos é o do crescimento das práticas de teletrabalho. Morgan (2004) apoia-se em uma afirmação de Bill Gates para prever que, até o ano de 2050, metade da população ativa no mundo estará atuando nessa forma de trabalho. Segundo estimativas da Sociedade Brasileira de teletrabalho - Sobratt (2007), já existem mais de 3 milhões de pessoas que, em algum grau, atuam nesse tipo de regime no Brasil.

De acordo com Morgan (2004), o conceito de trabalho flexível pode assumir diferentes tipos de conotação, entre as quais: locais flexíveis, horários flexíveis ou contratos flexíveis. Haveria, segundo esse autor, uma diversidade de arranjos que, combinando esses três tipos de flexibilidade, poderiam ser denominados teletrabalho.

Autores como Martínez-Sánchez et al (2007) e Tremblay (2002) adotam definições mais genéricas para o teletrabalho, como a de que se trata de uma forma de trabalhar mediada pela TIC, em que, pelo menos, parte das atividades é desenvolvida fora do escritório da organização. Outros, como Costa (2004) e Wilks e Billsberry (2007), chamam a atenção para o quanto a simples diferenciação em função do distanciamento do escritório da empresa se mostra limitada para refletir toda a gama de situações que podem ser enquadradas no conceito de teletrabalho. Podem ser classificados como teletrabalhadores, por exemplo, tanto empregados quanto autônomos que atuam nesse tipo de configuração, cujas condições são diversas (QVORTRUP, 1998). Garrett e Danziger (2007), por sua vez, diferenciam três tipos principais de teletrabalhadores: aqueles que trabalham a maior parte do tempo em casa ou em escritórios satélites, na modalidade que tais autores denominam fixed-site telework; aqueles que atuam em uma combinação de ambientes diversos, incluindo a casa, os escritórios da empresa e o trabalho de campo, o que é caracterizado por esses autores como flexiwork; e aqueles que atuam a maior parte do tempo realizando trabalho de campo em local variável, na configuração nomeada por Garrett e Danziger como mobile telework.

Hislop e Axtell (2007) sugerem que existem diferenças importantes nos desafios enfrentados pelos indivíduos que atuam nesses tipos de configuração, sobretudo, quando se comparam os que trabalham regularmente de casa com os que atuam de forma mais nômade. Em uma revisão da literatura sobre o tema, Costa (2004) ressalta que, além da localização física, é preciso também levar em conta as diferenças relativas a outras 
dimensões, tais como o nível de utilização da tecnologia, o quanto a atividade é intensiva em conhecimento e o tipo de contrato de trabalho mantido.

Este estudo focaliza especificamente o caso de teletrabalhadores da Shell Brasil, empresa que, desde 2000, instituiu o regime home-office (MORGAN, 2004) para parte de seus empregados. Trata-se, então, de indivíduos que realizam a maior parte do trabalho na própria residência; fora, portanto, do escritório da empresa ou de qualquer outro tipo de ambiente físico profissional (exemplo: escritório de clientes), correspondendo a um caso especial do que Garrett e Danziger (2007) classificaram como fixed-site teleworkers.O objetivo do estudo é identificar que consequências os indivíduos percebem ter tal forma de atuação trazido para o seu trabalho e para sua vida pessoal. A análise baseou-se em entrevistas semiestruturadas com 15 funcionários que atuam no eixo Rio/São Paulo. O estudo faz parte de uma linha de pesquisa mais ampla, cujo objetivo é analisar os efeitos sobretudo, para os indivíduos - das diversas formas de flexibilização das relações de trabalho, tais como a terceirização, o teletrabalho e o autoemprego.

O artigo começa com uma revisão da literatura especializada, analisando as vantagens e as desvantagens dessa modalidade de atuação profissional, tanto para as empresas quanto para os indivíduos. Posteriormente, são descritos a metodologia do estudo e o contexto do teletrabalho na Shell Brasil. Em seguida, são apresentados os resultados e as conclusões do estudo.

\section{Vantagens e desvantagens do teletrabalho}

Pesquisadores como Costa (2004, 2007), Silva (2008), Tombari e Spinks (1999) e White et al (2003) têm estudado as consequências das novas práticas de flexibilização do trabalho, entre as quais se inclui o teletrabalho. Porém, não há consenso quanto aos efeitos dessas práticas na sociedade, nas organizações e nos indivíduos. No caso específico dos empregados teletrabalhadores, autores como Tietze (2005) citam efeitos negativos percebidos pelos indivíduos, tais como maior controle exercido pelas organizações, menor criatividade nas atividades executadas e jornadas de trabalhos que tendem a se prolongar além dos horários tradicionais. No caso dos teletrabalhadores autônomos, a literatura sobre o tema aponta outras consequências negativas, tais como o maior risco de perda de identidade e a dificuldade de construir carreira, enquanto a situação dos empregados que atuam em casa tende a ser vista de forma mais positiva, em função da flexibilidade proporcionada, sem que haja tantas perdas associadas (QVORTRUP, 1998; SILVA, 2008). Outros autores, como Dewett e Jones (2000) e Tombari e Spinks (1999), apontam vantagens que algumas das novas configurações do trabalho - sobretudo, as mediadas pela tecnologia - trazem para os indivíduos: melhor entendimento dos processos organizacionais, compartilhamento de conhecimentos, agilidade na execução das tarefas e equilíbrio entre trabalho e vida pessoal. Diferentes estudos têm se dedicado também a apontar como essa mediação da tecnologia conduz a mudanças na dinâmica espaçotemporal, trazendo para os indivíduos a percepção de benefícios e dificuldades nas suas relações com o trabalho (SILVA; WETZEL, 2007a, 2007b; VERGARA; VIEIRA, 2005). Outras pesquisas sugerem que essas novas configurações de trabalho - e mais particularmente o teletrabalho - influenciam a dinâmica das identidades (BROCKLEHURST, 2001; MARSH; MUSSON, 2008) e da manifestação da subjetividade dos indivíduos (COSTA, 2004, 2007). Há, ainda, quem, como Papalexandris e Kramar (1997), acredite que essas novas configurações podem gerar benefícios para toda a sociedade, elevando a produtividade e a competitividade e reduzindo o desemprego.

Em pesquisas realizadas em diferentes empresas que adotaram o teletrabalho para seus funcionários, Mitchell (1996) identificou que os aspectos que influenciam as possibilidades de sucesso dessa mudança podem ser classificados como parâmetros macro e micro. Os parâmetros micro são aqueles relacionados ao indivíduo e à tarefa. Já os parâmetros macro referem-se à organização, ao setor e à região onde ela atua. No nível micro, o autor destaca sete parâmetros que parecem influenciar diretamente as chances de sucesso do teletrabalhador: a pessoa - atitudes, preferências, habilidades e motivações; o contexto do vínculo de trabalho - se o indivíduo é funcionário de uma empresa, se é autônomo e trabalha para várias empresas ou se é sócio de empresa virtual; a tarefa - a natureza da atividade, se ela exige criatividade ou é repetitiva, se é ou não estruturada, se exige concentração ou demanda comunicação intensa; a natureza dos relacionamentos externos - se a pessoa se relaciona com clientes, fornecedores ou com empresas do mesmo setor e o que tais elementos externos esperam 
desse relacionamento; o contexto da utilização do espaço - se o indivíduo trabalha em casa $100 \%$ do tempo ou apenas parcialmente, / se o indivíduo trabalha em casa em tempo integral ou apenas parcialmente, se tem acesso a algum escritório da empresa, que tipo de espaço tem para trabalhar em casa e qual é o grau de receptividade dos familiares; a natureza dos relacionamentos internos - se a motivação do teletrabalhador depende da relação com o supervisor e demais membros da equipe e como é o estilo de trabalho na equipe, ou seja, qual é o grau de interdependência dos membros; o contexto tecnológico - se o teletrabalhador e os demais membros da organização utilizam com frequência recursos tecnológicos e estão confortáveis com o trabalho à distância e quais são os custos e a qualidade dos recursos disponíveis.

Focalizando mais o nível macro, McGrath e Houlihan (1998) argumentam que o teletrabalho seria mais adaptável em uma empresa cujo sistema de gestão se diferencie do modelo convencional da organização moderna. No que tais autores classificam como um modelo virtual ou pós-moderno, os indivíduos tenderiam a encontrar maior autonomia para planejar e desenvolver suas atividades, em função do maior nível de descentralização.

Perin (1998) pondera que a migração para o regime de teletrabalho provoca mudanças no contrato psicológico do indivíduo com a organização, além de afetar as suas relações com a família e a comunidade. Rousseau (1995) define contrato psicológico como o conjunto de crenças pessoais, mantidas em função de promessas reais ou inferidas, acerca da relação que o indivíduo mantém com a organização, ou seja, daquilo que ele acredita ser o seu conjunto de direitos e deveres nessa relação. Trata-se, portanto, de um conjunto de percepções de natureza subjetiva que podem frustrar expectativas e até levar a um sentimento de ruptura nessa relação, requerendo que a empresa se preocupe em deixar bem claro em que bases foi firmado o acordo de trabalho. No caso do teletrabalho, essa preocupação deve ser ainda maior, segundo Perin (1998), em função das mudanças que isso representa e do distanciamento que essa forma de atuação tende a provocar na relação entre o indivíduo e o restante da organização, incluindo seus supervisores. Para Golden (2007), essa preocupação da empresa com os efeitos na relação de trabalho não deve focalizar somente os teletrabalhadores. Esse autor observa que a existência de empregados teletrabalhadores regulares na empresa pode ter um efeito negativo também quanto ao nível de satisfação dos indivíduos que permanecem trabalhando no escritório. Entre outras razões, estes podem experimentar uma sensação de aumento na carga de trabalho, ter dificuldade de interação com os colegas distantes e, até mesmo, desenvolver uma percepção mais negativa de justiça.

A literatura sobre teletrabalho aponta a redução de custos dos escritórios como um dos primeiros objetivos das empresas ao adotarem esse tipo de solução (BENTLEY; YOONG, 2000; MARTÍNEZ-SÁNCHEZ et al, 2007; NILLES, 1996; PATRICKSON, 2002). Segundo Nilles (1996), essa pode ser uma vantagem também para o trabalhador, uma vez que há a tendência deste reduzir seus gastos com deslocamentos e alimentação. Entretanto, o autor ressalta que essa redução nem sempre é total, pois os teletrabalhadores passam a frequentar shopping centers, supermercados e outros estabelecimentos comerciais próximos de suas residências, para os quais acabam redirecionando seus gastos.

Bentley e Yoong (2000) e Patrickson (2002) indicam outros motivos que levam as organizações a promoverem a migração de seus funcionários para o regime home-office, tais como a retenção de talentos e a melhoria da qualidade de vida dos indivíduos.

A retenção de talentos se deveria principalmente à possibilidade de propiciar aos funcionários oportunidades de conciliar as atividades profissionais com a vida pessoal. Além disso, profissionais mais próximos da aposentadoria poderiam dedicar-se a outras atividades, sem deixar de contribuir com o seu conhecimento acumulado.

A melhoria na qualidade de vida tem sido um dos argumentos mais usados pelas empresas para convencerem funcionários a migrar para essa modalidade. Tremblay (2002) também observa que ela é uma das vantagens percebidas pelos teletrabalhadores, principalmente, pela flexibilidade de horários e por poderem realizar atividades de interesse pessoal. No entanto, a autora também constata que isso traz um custo associado, uma vez que o horário flexível obriga as pessoas à melhor gestão de suas atividades. Como nem todos se sentem preparados para a disciplina da autogestão, surgem dificuldades de lidar com uma nova lógica de tempo e 
espaço. Tietze (2005) também encontrou teletrabalhadores que perderam os limites espaçotemporais que separavam o trabalho da rotina doméstica. Alguns começaram a trabalhar além das horas previstas na jornada normal das empresas, passando também a disputar o espaço de casa com os membros da família. Ainda assim, segundo Tremblay (2002), o teletrabalho costuma ser mais visto como atrativo por pessoas casadas e com filhos do que por solteiros, pois diminui o tempo gasto em deslocamentos, viabilizando um aumento do tempo gasto com a família, principalmente, no caso das mulheres.

Perin (1998) pondera que, culturalmente, as mulheres tendem a assumir maior número de tarefas da casa, tornando-as menos disponíveis para a organização. Mesmo em lares onde os homens participam mais ativamente na divisão das atividades domésticas, estes assumem no máximo $40 \%$ delas. Isso levaria as mulheres a serem mais propensas a aderir ao teletrabalho. Ainda segundo Haddon (1998), a mulher pode optar pelo teletrabalho quando do nascimento de filhos e, mais tarde, retornar ao trabalho tradicional na empresa. Por outro lado, autores como Hartig, Kylin e Johanson (2007), Hilbrecht et al (2008) e Osnowitz (2005) observam que as mulheres teletrabalhadoras tendem a ter mais dificuldades do que os homens para separar as atividades profissionais da rotina doméstica. Como consequência, elas também tendem a ser mais suscetíveis a perceber os custos pessoais - e não somente os benefícios - associados ao teletrabalho na modalidade home-office. Hilbrecht et al (2008) verificaram, por exemplo, que no esforço de conciliar os papéis de profissional e de mãe, as mulheres teletrabalhadoras raramente convertem a flexibilidade obtida com o trabalho realizado em casa em cuidados com elas mesmas - sempre acabam priorizando o trabalho e as demandas da família.

Marsh e Musson (2008), no entanto, encontraram indícios de que essa dificuldade de separar a vida profissional da vida doméstica vivida mais intensamente pelas mulheres pode estar se modificando, à medida que os homens teletrabalhadores passam a conviver com a necessidade de, no mesmo espaço da casa, estabelecer um melhor equilíbrio entre suas identidades como pais e profissionais. Em um estudo qualitativo analisando as impressões de homens com tal perfil, essas autoras constaram que alguns deles adotavam um discurso emocional sobre sua condição de profissional-pai, tradicionalmente associado às mulheres.

Costa (2007) e Tremblay (2002) observaram, por sua vez, que a disponibilidade do(a) teletrabalhador(a) para os filhos pode ser apenas parcial; ou seja, a maior proximidade da família não significa que ele ou ela sempre conseguirá exercer livremente o cuidado com os filhos durante o horário de trabalho. Haddon (1998) também pondera que a flexibilidade de horário não implica liberdade para priorizar as atividades que o indivíduo gostaria de realizar: os teletrabalhadores têm que negociar com supervisores, familiares, colegas e clientes o espaço e o tempo para desempenhar as atividades inerentes a cada papel, definindo os limites entre as diferentes esferas de sua vida.

Segundo Tietze (2002), o esforço de restabelecer as fronteiras espaço-temporais entre casa e trabalho leva os indivíduos a desenvolverem mecanismos como, por exemplo, o estabelecimento de rituais especiais ou o uso do dress-code, isto é, códigos de vestimentas utilizados para delimitar a sua disponibilidade para os familiares e para a rotina doméstica em geral. A autora cita o exemplo de homens que adotavam o uso de gravatas ou o ato de se barbear como um tipo de código para mostrar aos demais membros da casa que estavam trabalhando; ou ainda, o caso de mulheres que, pelo mesmo motivo, maquiavam-se ou selecionavam modelos de brincos ou cores especiais de batom. Nas pesquisas de Tietze, havia também aqueles que aderiam a cartazes ou sinais colocados na porta do cômodo utilizado como área de trabalho, para indicar os momentos em que podiam ou não ser interrompidos.

Mann, Varey e Button (2000) levantaram alguns dos impactos percebidos por empregados teletrabalhadores quanto às vantagens e desvantagens para suas vidas pessoal e profissional. Entre as principais vantagens, na ordem em que foram mais citadas, destacam-se: menor necessidade de deslocamento; maior liberdade e flexibilidade; melhor ambiente de trabalho; menos distrações; menor custo; liberdade para usar roupas confortáveis; distanciamento do jogo político do escritório; e facilidade para cumprir tarefas domésticas. Entre as principais desvantagens, na ordem em que foram mais citadas, destacaram-se: isolamento; aumento da jornada de trabalho; falta de suporte; impossibilidade de faltar por motivo de doença; dificuldade de progresso na carreira; e elevação nos custos. 
Nas vantagens, observa-se que o menor deslocamento e a maior flexibilidade são os primeiros itens, enquanto a facilidade de cumprir tarefas domésticas é o último, o que talvez revele que nem todo o tempo liberado seja de fato utilizado em prol da rotina da família. Observa-se também que se, por um lado, os indivíduos veem positivamente a distância do jogo político corporativo, por outro, esse mesmo fator aumenta a sensação de isolamento, a desvantagem mais citada.

Mann, Varey e Button (2000) comentam que a sensação de isolamento talvez se deva, em parte, à redução da comunicação face a face, rica em aspectos não-verbais, e ao aumento da comunicação mediada pela tecnologia, pobre nesse aspecto, apesar de mais flexível em termos de tempo e espaço. Para tais autores, a comunicação face a face permite maior compartilhamento de sentidos. Entretanto, a principal limitação percebida em termos da qualidade da comunicação mediada pela TIC seria a impossibilidade de expressão de sentimentos, reduzindo a intimidade e desumanizando a relação entre os colegas de trabalho, o que, segundo tais autores, pode afetar a motivação e o comprometimento dos indivíduos.

Outro fator de destaque na lista de Mann, Varey e Button (2000) é o custo. Tal como verificado por Nilles (1996), trata-se de um aspecto visto como vantagem por alguns indivíduos e como desvantagem por outros. Uma razão que o coloca no lado das desvantagens é o aumento dos gastos com energia e com a infraestrutura doméstica, além da transferência de responsabilidade para o indivíduo do gasto com outros recursos antes disponíveis no escritório, tais como os materiais de uso e o cafezinho. Essa visão de perda de infraestrutura se revela também quando os indivíduos indicam como desvantagem a falta de suporte da empresa na solução de problemas, principalmente, os relacionados a recursos tecnológicos.

Tais autores também observaram que os teletrabalhadores tendem a não faltar às obrigações, mesmo quando doentes - exceto, se hospitalizados. Algumas empresas podem ver isso como um aspecto positivo, pois a preocupação com o absenteísmo se torna significativamente menor. No entanto, na visão de Mann, Varey e Button (2000), esse "presenteísmo" é preocupante, por representar uma ameaça à saúde do trabalhador e expor a empresa ao risco da perda de qualidade do trabalho.

Os resultados obtidos por Mann, Varey e Button (2000) também foram constatados em outros estudos. Ward e Shabha (2001) apontam ainda a redução do estresse e um maior controle pessoal como vantagens relevantes para os teletrabalhadores. Nas desvantagens, esses autores destacam a possibilidade de perda de identificação e de compartilhamento de valores do indivíduo com a companhia. Tremblay (2002), por sua vez, inclui o aumento da produtividade como outra vantagem apontada pelos indivíduos. Como desvantagem adicional, os participantes de suas pesquisas identificam uma possível perda de prestígio em suas respectivas empresas. Isso reforça um dos itens mais citados no estudo de Mann, Varey e Button (2000): a dificuldade de ascensão na carreira, principalmente, como decorrência da falta de visibilidade na empresa e da inexistência de parâmetros de avaliação de desempenho compatíveis com as características do teletrabalho.

Quanto a esse último aspecto, Tremblay (2002) acrescenta que, muitas vezes, os supervisores são despreparados para avaliar corretamente os teletrabalhadores, pois isso envolve uma modalidade de trabalho relativamente nova. Essa autora também verificou que as metas atribuídas aos teletrabalhadores, frequentemente, são de $10 \%$ a $20 \%$ maiores, quando comparadas com as metas dos indivíduos que trabalham em regime convencional, isto é, nas dependências das empresas. Ainda de acordo com Martinez-Sánchez et al (2007), a falta de preparação dos gerentes tem sido mencionada na literatura especializada como uma das causas mais importantes de problemas com a implementação do teletrabalho nas empresas.

Em empresas estudadas por Felstead, Jewson e Walters (2003), os teletrabalhadores e os respectivos supervisores enfrentavam dificuldades para negociar o modus-operandi em termos de tempo e espaço para a realização de atividades, principalmente, em função do problema da visibilidade. Para os teletrabalhadores, o fato de os supervisores não os observarem no mesmo espaço físico, daria a conotação de que eles não estariam efetivamente trabalhando. Os supervisores também reclamaram da falta de visibilidade do desempenho de seus subordinados, dificultando a comunicação e o espírito de equipe. A solução encontrada por alguns supervisores foi agendar visitas esporádicas à residência dos indivíduos, o que, além de não gerar o resultado esperado, provocava constrangimentos. Uma mulher preocupava-se com a opinião dos vizinhos quanto a um homem 
(supervisor) entrar em sua casa na ausência do cônjuge. Outro teletrabalhador reclamou do trabalho extra que tinha para arrumar a casa para receber o supervisor no dia da visita. Algumas empresas desenvolveram mecanismos de vigilância dos funcionários, mas não lograram êxito. De fato, os supervisores alegaram que o pré-requisito básico para o bom desempenho do teletrabalho é a confiança no teletrabalhador.

Ainda segundo Felstead, Jewson e Walters (2003), várias empresas tentam disseminar sua cultura para os teletrabalhadores por meio de ritos como reuniões ou convenções periódicas. Porém, nas pesquisas daqueles autores, os teletrabalhadores reclamaram dessas reuniões, alegando que não tinham espaço para abordar questões que para eles seriam relevantes. Além disso, nas ocasiões em que visitavam o escritório da empresa com algum propósito específico, toda a agenda deles era modificada por supervisores e colegas que, pelo simples fato de perceberem a sua disponibilidade, os chamavam para debater diversos assuntos não programados.

Com relação ao uso do espaço físico, Fulton (2002) aponta que os indivíduos sentem necessidade de replicar em casa as condições de que dispunham no escritório da empresa. Para isso, alguns imprimem documentos e os organizam em locais pouco usuais, como camas ou estantes antes utilizadas para decoração. Outros compõem uma maleta com os objetos de que precisam para trabalhar e passam a carregá-la para todo lugar, como se ela fosse o escritório.

Büssing (1998) também avalia diversos fatores que podem influenciar a motivação, o estresse e a qualidade de vida dos teletrabalhadores, destacando, entre eles, as características: da sociedade - envolvendo aspectos como custos imobiliários, de energia, de mão de obra e, até mesmo, a qualidade do ar; da organização - tais como a estrutura e o tipo de tecnologia; do indivíduo - envolvendo aspectos demográficos e psicossociais; e do contexto do teletrabalho - tais como a gestão de resultados, a qualidade da comunicação, o treinamento de teletrabalhadores e supervisores, o suporte técnico, a estrutura de salários e benefícios e o tipo de alocação de tempo.

Entre esses fatores e a qualidade de vida dos teletrabalhadores haveria, ainda, variáveis mediadoras, entre elas o grau de concentração, de flexibilidade e de controle do tempo. Nesse sentido, o autor subdivide a qualidade de vida do teletrabalhador em duas dimensões: a qualidade no trabalho e fora dele. No âmbito do trabalho, a qualidade de vida seria reforçada por aspectos como o ganho de produtividade, a possibilidade de redução de custos e as reações afetivas às atividades executadas. Fora da esfera do trabalho, a qualidade de vida seria afetada por aspectos como o tempo com a família, o tempo de lazer e a economia de gastos pessoais.

Finalmente, Golden e Veiga (2005) verificaram que os teletrabalhadores tendem a se sentir mais satisfeitos com a sua condição quando executam tarefas que exigem menor interdependência com seus pares e quando possuem maior autonomia de decisão sobre a forma de execução das tarefas. Além disso, os mesmos autores verificaram que o nível de satisfação tende a ser proporcional ao número de horas dedicadas ao trabalho à distância, ainda que até um determinado patamar. Quando esse número de horas é excessivo, cai o nível de satisfação do teletrabalhador, talvez, em função da já citada sensação de isolamento.

\section{Metodologla}

Este artigo apresenta o resultado de um estudo sobre a modalidade do teletrabalho em regime de home-office na Shell Brasil. Trata-se, portanto, de um estudo de caso único, de natureza descritiva (VERGARA, 1997), que analisou as percepções que os próprios indivíduos têm de sua atuação como teletrabalhadores, reveladas durante entrevistas em profundidade. A coleta de dados foi complementada pelo levantamento de fontes documentais da empresa, visando identificar como o teletrabalho foi por ela estruturado. A Shell Brasil foi escolhida por ter sido uma das primeiras empresas no país a adotar - desde 2000 - oficialmente essa modalidade de trabalho para alguns funcionários. Além disso, a escolha decorreu de uma maior facilidade de acesso a dados e pessoas da empresa por parte de um dos pesquisadores, ele próprio um funcionário que durante certo período também foi teletrabalhador. 
Foram entrevistados 15 funcionários que atuam no eixo Rio/São Paulo, trabalham em regime home-office há vários anos e respondem por atividades locais e globais. Quando da escolha dos entrevistados, o que se buscou foi retratar a diversidade de perfis dos funcionários que atuam nessa modalidade na empresa em questão, embora a seleção final tenha sido determinada, principalmente, pela acessibilidade. A tabela 1 apresenta o perfil dos entrevistados, destacando aspectos como sexo, idade, estado civil, cidade onde residem, número de filhos, números de pessoas na residência e tempo como teletrabalhador. Todos estão há mais de cinco anos na empresa. A maioria migrou para o home-office em 2000, quando da implantação na Shell. Apenas dois foram contratados diretamente nesse regime. O entrevistado E6 declarou que já atuava na modalidade há 11 anos, ou seja, antes da empresa criar uma política oficial nesse sentido, pois atendia uma região do interior onde não existia um escritório da Shell. No grupo de entrevistados, três deles, além de teletrabalhadores, são também supervisores de outros funcionários. Dessas 15 pessoas ouvidas -12 homens e três mulheres -10 são casadas, nove das quais morando com os filhos. Apenas um desses entrevistados não mora no Grande do Rio nem na Grande São Paulo. Apenas um indivíduo tinha menos de 30 anos por ocasião das entrevistas; todos os demais estavam na faixa entre 34 e 43 anos.

Tabela 1- Perfil dos entrevistados

\begin{tabular}{|c|c|c|c|c|c|c|c|}
\hline Entr. & $\begin{array}{l}\text { Idade/ sexo/ } \\
\text { estado civil }\end{array}$ & Cidade residência & $\begin{array}{c}\text { Residentes } \\
\text { domicílio }\end{array}$ & Filhos & $\begin{array}{l}\text { Tempo } \\
\text { cia. }\end{array}$ & Supervisor & $\begin{array}{c}\text { Tempo no } \\
\text { teletrabalho }\end{array}$ \\
\hline E1 & 42/M/Cãs. & Rio de Janeiro & 4 & 2 & $12 \mathrm{a}$. & Não & 7 anos \\
\hline E2 & 36/M/Cãs. & Rio de Janeiro & 3 & 1 & $6,5 \mathrm{a}$. & Não & 6,5 anos \\
\hline E3 & 34/M/Solt. & São Paulo & 1 & 0 & 8 a. & Não & 7 anos \\
\hline E4 & 36/M/Cãs. & S.B.Campo, SP & 4 & 2 & $11,8 \mathrm{a}$. & Não & 7 anos \\
\hline E5 & 43/M/Cãs. & Rio de Janeiro & 5 & 2 & $20 \mathrm{a}$. & Sim & 7 anos \\
\hline E6 & 39/M/Cãs. & Americana, SP & 4 & 2 & 19 a. & Não & 11 anos \\
\hline E7 & 39/M/Cãs. & São Paulo & 2 & 0 & $10 \mathrm{a}$. & Não & 7 anos \\
\hline E8 & 42/M/Cãs. & Niterói, RJ & 5 & 2 & $17 \mathrm{a}$. & Não & 7 anos \\
\hline E9 & 30/F/Solt. & São Paulo & 2 & 0 & $5 \mathrm{a}$. & Não & 5 anos \\
\hline E10 & 36/M/Solt. & São Paulo & 1 & 0 & $12 \mathrm{a}$. & Sim & 7 anos \\
\hline E11 & 34/F/Cãs. & São Paulo & 4 & 1 & 6,5 a. & Não & 6,5 anos \\
\hline E12 & 39/F/Solt. & São Paulo & 1 & 0 & $14 \mathrm{a}$. & Não & 7 anos \\
\hline E13 & 26/M/Solt. & São Paulo & 2 & 0 & $6 \mathrm{a}$. & Não & 6 anos \\
\hline E14 & 35/M/Cãs. & Niterói, RJ & 3 & 1 & $14 \mathrm{a}$. & Sim & 4 anos \\
\hline E15 & 43/M/Cãs. & S.Caetano Sul, SP & 3 & 1 & $18 \mathrm{a}$. & Não & 7 anos \\
\hline
\end{tabular}

Fonte: elaborada pelos autores.

A entrevista realizada foi do tipo focada (CRESWELL, 1997). Isto é, embora não estruturadas, a partir de um roteiro básico de apoio, as questões foram construídas em torno de um tema específico - a experiência do entrevistado como teletrabalhador. O roteiro abordava: o tempo de atuação no teletrabalho; a natureza das atividades; as razões para a migração; as mudanças que foram feitas na residência; a receptividade dos membros da família; a jornada de trabalho após a migração; o relacionamento com supervisores e membros da equipe; o suporte e os recursos disponibilizados pela empresa; os impactos favoráveis e desfavoráveis percebidos com a mudança; e as expectativas quanto a voltar ou não ao regime tradicional.

As entrevistas, com duração entre 30 e 45 minutos, foram realizadas nos meses de fevereiro e março de 2007 em dependências da empresa ou em locais públicos. A escolha desses locais se deveu a questões de ordem prática e à tentativa de preservar o ambiente domiciliar dos entrevistados. As entrevistas foram gravadas em meio digital e transcritas. O conteúdo foi analisado e categorizado com o auxílio do software Atlas TI. Em uma primeira leitura desse conteúdo, surgiram 26 categorias de análise referentes às consequências percebidas pelos indivíduos, com relação à sua condição como teletrabalhadores, as quais emergiram do conteúdo das falas dos 
entrevistados. Em etapa posterior, essas categorias foram reagrupadas, aproximando-se os conteúdos afins, resultando em outras 15 categorias, a saber: comunicação e integração; recursos tecnológicos; visibilidade; impacto na carreira; mudança de comportamento; adesão ao teletrabalho; contrato psicológico e relação com o trabalho; flexibilidade de horário; redução de custos; espaço físico; natureza do trabalho; produtividade; relacionamento com a família; relacionamento com amigos; e equilíbrio entre vida pessoal e trabalho.

$\mathrm{Na}$ análise final, essas 15 categorias foram organizadas em três grandes grupos, relativos às consequências: para a forma de atuação na empresa e para a carreira; para a relação com o trabalho; e para a vida pessoal e para as relações sociais e em família.

O conteúdo das três categorias finais é analisado a seguir, após a apresentação do contexto do teletrabalho na Shell Brasil.

\section{0 contexto do teletrabalho na Shell Brasll}

A Shell é uma multinacional de origem anglo-holandesa, voltada para a prospecção e distribuição de combustíveis, presente em 140 países, com cerca de 102 mil funcionários. A Shell Brasil iniciou suas operações em 1913, atua em todo o território nacional e contava, à época do estudo, com aproximadamente 1.660 funcionários, dos quais $242 \mathrm{em}$ home-office.

A implantação do teletrabalho na empresa ocorreu em 2000, como parte de um programa global. Inicialmente, foram realizadas palestras de conscientização dos funcionários, ministradas por consultores. Entre os principais objetivos declarados pela companhia, destacavam-se a redução de custos de aluguel, de energia e de impostos e ganhos de produtividade a serem obtidos com a melhor performance dos funcionários, que estariam mais próximos dos clientes e fornecedores. Num primeiro momento, as áreas prioritárias para a migração foram aquelas em que os funcionários já não frequentavam os escritórios diariamente, com rotina de visitas e viagens constantes. Posteriormente, houve ampliação para outras funções e algumas pessoas já foram contratadas para atuar nesse regime.

A empresa deixa claro que o regime home-office: (a) depende primordialmente do negócio e das condições de trabalho de uma determinada equipe; (b) só pode ocorrer por meio de um acordo entre o funcionário e a empresa. Além disso, a remuneração e a avaliação de desempenho do teletrabalhador devem ser semelhantes às do funcionário tradicional.

Para propiciar ao teletrabalhador as mesmas condições de trabalho do funcionário tradicional, a Shell garante os seguintes recursos: impressora e filtro de linha; notebook; caixa postal de correio convencional em nome da Shell, próximo à residência do teletrabalhador, para envio e recebimento de documentos; caixa postal de fax (fax virtual); telefone celular (se aplicável); verba de R $\$ 750$ para adequação do espaço da residência, de modo a garantir as condições de segurança e ergonomia (concessão única); acesso à internet em banda larga; verba de $\mathrm{R} \$ 150$ mensais para despesas com energia elétrica e com telefonia fixa, podendo aumentar, se comprovados gastos superiores; reembolso de despesas com correio; e materiais de escritório.

A caixa postal de fax corresponde a um número de telefone em que um documento é recebido via fax e, depois de digitalizado por empresa terceirizada, anexado a um e-mail que segue para o funcionário. A companhia, entretanto, não fornece equipamento para envio de fax.

A empresa também define as responsabilidades do teletrabalhador e do seu supervisor. São atribuições do supervisor: registrar mudanças na forma de trabalho; priorizar a disciplina, o desenvolvimento próprio e o da equipe; implementar rotinas acordadas com a equipe; monitorar visitas ao campo; manter a equipe integrada e motivada; trabalhar as dificuldades de adaptação da equipe e incentivar os valores de autonomia, flexibilidade e eficácia; disseminar/seguir os princípios da companhia. 
São atribuições do funcionário: priorizar a disciplina, a automedição e o desenvolvimento próprio; trabalhar suas deficiências de adaptação; realizar backups periódicos; garantir que o local de trabalho atenda às diretrizes de HSSE (healthy, safety, security and environment); e seguir os princípios da companhia.

A Shell recomenda, ainda, a realização de encontros presenciais entre supervisor e subordinados, de modo a promover a integração da equipe e garantir o alinhamento com a estratégia e os objetivos da empresa. Essas reuniões, que podem ser mensais, bimestrais ou trimestrais, são realizadas em hotéis, cafeterias e ou em restaurantes, sem que haja, no entanto, um acompanhamento formal por parte da empresa.

\section{Consequênclas para a forma de atuação na empresa e para a carreira}

Em parte, os entrevistados neste estudo tenderam a avaliar as consequências de sua migração para a condição de teletrabalhadores em função dos efeitos dessa mudança na sua forma de atuação na empresa e na relação de trabalho com ela estabelecida. Isso diz respeito, principalmente, aos possíveis desdobramentos em termos de oportunidades de carreira. Contudo, ao analisarem esses aspectos, não mencionaram somente as consequências para si próprios, mas também para a empresa.

A maioria dos entrevistados considera que um dos objetivos da organização ao adotar o regime home-office, a redução de custos corporativos, tem sido atendido. O principal ganho seria a economia com ativos fixos, obtida com a redução dos espaços de escritórios, geralmente, localizados em áreas nobres de grandes cidades. No entanto, a redução de despesas também é vista como significativa ("eu deixei de tomar café na empresa, [...] de usar ar-condicionado, de usar uma vaga de garagem..." - E5). Outro benefício corporativo percebido, embora não explicitamente declarado como objetivo, é a maior inserção dos funcionários do Brasil na visão global da Shell. Corroborando a visão de McGrath e Houlihan (1998), predomina também a opinião de que um fator que ajudou a empresa a atingir seus objetivos foi o fato dela já possuir um modelo de organização relativamente flexível, principalmente, considerando-se a realidade dos que fizeram a migração.

Muitos já passavam grande parte do tempo fora dos escritórios, em contato com o cliente. Conforme observou Mitchel (1996), a natureza da tarefa é vista pelos entrevistados como um facilitador de sua adaptação. Como atuam "na linha de frente", em contato com clientes, há momentos em que as tarefas a serem cumpridas demandam flexibilidade, com muitas visitas de campo e a realização de negociações. Entretanto, alguns indivíduos questionam se o objetivo corporativo de promover maior aproximação do cliente foi, de fato, alcançado, já que "o tempo que as pessoas gastavam indo pro escritório passaram a gastar dentro de casa" (E10). Uma razão apontada para isso é que, além das atividades de campo, há rotinas de planejamento e de processamento de informações que ocupam grande parte do tempo e que exigem concentração, seja no escritório ou em casa. Porém, mesmo nessas atividades, quase todos consideram que se tornaram mais produtivos após a migração. Os motivos são, no entanto, diversos. Alguns dizem que trabalham melhor, mais bem dispostos e com mais foco:

No escritório, você está passando mal, ou tem [...] outras preocupações. Você não consegue focar, mas ao mesmo tempo, você não pode sair do escritório [...]. No home-office, você pode focar numa coisa que está te incomodando e, resolvido isso, [...] executar aquela coisa com uma cabeça muito melhor. (E2)

Outros atribuem a maior produtividade ao afastamento do ambiente tumultuado do escritório, já que a empresa utiliza um tipo de layout aberto, do tipo aquário, em que todos se veem e se ouvem o tempo todo. Para o entrevistado E5, por exemplo, o ambiente de casa, mais relaxado e agradável, estimula a criatividade. Contudo, a distância do escritório parece ser uma vantagem relativa, pois não libera totalmente o indivíduo das interferências do ambiente corporativo: "porque, [...] trabalhando home-office, você recebe ligação, tem interferência externa de clientes, de colegas, de subordinados, da própria sede" (E5). Além disso, como se verá adiante, o indivíduo não está livre das interferências do próprio ambiente doméstico. 
Apesar da visão predominantemente positiva quanto à forma de atuação dos indivíduos na empresa, são percebidas desvantagens no teletrabalho; dentre as quais se destacam as dificuldades de comunicação e de integração e a menor visibilidade.

De modo geral, os entrevistados consideram que o fluxo de informações de que necessitam para realizar suas atividades acontece de forma organizada e eficiente. Há, porém, situações em que a distância física e a comunicação quase restrita ao meio eletrônico criam dificuldades. Uma delas é a falta de sincronismo que faz com que nem sempre se consiga contactar as pessoas da empresa quando é preciso, prejudicando o andamento do trabalho:

Você troca vários e-mails, quando uma ligação [...] ou um olho no olho bastaria. E, quando você não encontra a pessoa que você gostaria de falar na hora, você deixa o recado e a pessoa não te retorna, você esquece daquele assunto. (E5)

Corroborando o observado por Mann, Varey e Button (2000), percebe-se um empobrecimento da comunicação, por faltarem os recursos que o contato pessoal, cotidiano e menos formal possibilita. Esse empobrecimento da comunicação gera também dificuldades de compartilhar informações que, embora não se incluam entre as tarefas cotidianas, ajudam a entender o contexto e a cultura da empresa: "você descobre que um colega teu foi promovido ou foi demitido quatro meses depois" (E3).

Os encontros oficiais promovidos pela empresa parecem, ainda, insuficientes para criar o nível de integração desejável, tal como verificado por Felstead, Jewson e Walters (2003). Contudo, os entrevistados ponderam que uma solução para o problema seria eles mesmos promoverem mais encontros, como almoços e happy hours, incentivando uma comunicação mais informal e o compartilhamento de conhecimentos. Essa solução já vem sendo posta em prática por um grupo de São Paulo, embora seja algo viável apenas entre os que residem numa mesma cidade. A maioria considera que os supervisores são os principais responsáveis pelo esforço de integração, mas que nem sempre conseguem exercer esse papel. Alguns também se preocupam com a integração dos recém-migrados ao home-office, principalmente, os novos funcionários ("senão você vai acabar formando miniculturas, cada pessoa com o seu home-office" - E10).

Também concordando com Mann, Varey e Button (2000), um dos aspectos negativos mais mencionados nas entrevistas refere-se à falta de visibilidade do teletrabalhador. Ao se referirem a ele, os indivíduos parecem manifestar, porém, dois tipos distintos de percepções: a de estarem isolados socialmente do restante da organização e a de serem menos visíveis na gestão de recursos humanos. A seguinte narrativa ilustra a ideia de isolamento social:

você fica longe [...], não fica sabendo as coisas [...], passa a ser menos notado, menos visto, porque você não está lá todo dia, tomando cafezinho com as pessoas, tendo oportunidade de bater papo, almoçar junto [...]. Dependendo da sua frequência, você vira meio que um convidado quando chega ao escritório. (E8)

Quanto à visibilidade em termos da gestão de recursos humanos, a principal preocupação parece ser relativa à dificuldade de acompanhamento do desempenho e aos impactos que isso pode gerar para as perspectivas individuais de carreira:

Se a gente tem dois candidatos hoje, e um trabalha [...] dentro do escritório (...), o outro está homeoffice e os dois têm desempenhos iguais [...], o de home-office terá de gastar mais energia para demonstrar a mesma capacidade. (E10)

Não há, porém, consenso com relação a esse aspecto, já que alguns acreditam que, hoje, o que pesa nas chances de crescimento na empresa é a apresentação de resultados: "se você performar bem, você vai ser reconhecido; se você performar mal, independente da sua modalidade de trabalho [...], vai ter os mesmos problemas" (E14). Outros consideram que a realidade se aproxima do meio-termo: a empresa tem uma política de promoções centrada em resultados, mas o relacionamento pessoal parece ainda pesar significativamente nesse sentido. 
Parte da falta de visibilidade dos teletrabalhadores é atribuída também à dificuldade dos supervisores, em termos de acompanhar subjetivamente o desempenho e estabelecer com os indivíduos uma relação de confiança. Um entrevistado que, além de teletrabalhador, é também supervisor de equipe, apresenta mais claramente essa percepção:

A sensação que eu tenho com os meus subordinados é a vontade de saber se todo mundo está trabalhando o tanto que eu gostaria [...]; e eu só acabo sentindo se ela está trabalhando ou não quando a pessoa me entrega um resultado. (E10)

Assim como Felstead, Jewson e Walters (2003), esse mesmo entrevistado observa que tentativas de solução do problema por meio de mecanismos de monitoramento, como visitas à casa dos indivíduos ou observação dos acessos à rede, tendem a ser mal vistas na cultura da empresa.

Outros entrevistados criticam o fato de a avaliação seguir critérios quantitativos, baseados em medidas individuais que não levariam tanto em conta as interdependências que influem nos resultados. No entanto, tais críticas parecem ser dirigidas ao sistema geral de avaliação da companhia; não, propriamente, ao regime de teletrabalho. Há os que veem na simples adoção desse regime uma evolução da empresa, em termos da gestão do desempenho: "Isso confirma uma postura mais madura da companhia. Ela confia, ela delega mais" (E7).

A maioria mostrou-se satisfeita com as regras, instruções e recursos que a companhia disponibiliza para que possam exercer suas atividades. Porém, conforme apontado por Mitchel (1996), eles se mantêm sensíveis à falta ou inadequação de qualquer item ou procedimento que possa prejudicar sua produtividade ou reduzir a praticidade de ser um teletrabalhador. Um exemplo de recurso de que muitos sentem a falta é o aparelho para envio de fax. Alguns também consideram que deveriam ser disponibilizados palmtops para que as pessoas que executam rotinas externas não precisem se deslocar com seus notebooks.

Quanto aos procedimentos, uma entrevistada se queixou, por exemplo, de ter que levar pessoalmente itens com problemas (exemplo: o notebook) até a sede da companhia, para manutenção, arriscando-se a ter o equipamento roubado ou danificado, além de não receber item de substituição provisório durante o conserto. Essa entrevistada ponderou que a empresa poderia melhor orientá-la quanto às adaptações a serem efetuadas na residência.

\section{Consequênclas para a relação com o trabalho}

Em certos aspectos, a passagem para a condição de empregado teletrabalhador parece também levar os indivíduos a reverem sua relação com o trabalho. Para alguns entrevistados, a mudança tornou o trabalho mais "prazeroso".

Cabe aqui ressaltar que nenhum dos entrevistados escolheu voluntariamente trabalhar em home-office. Todos migraram para esse regime por recomendação da empresa ou já foram nele contratados. A maioria, porém, sente-se adaptada, revelando que preferia se manter nessa condição, mesmo que pudesse optar pela volta ao escritório. Em alguns casos, essa adesão ao teletrabalho se manifesta de forma tão plena que leva o indivíduo a questionar se, caso a empresa impusesse o retorno ao escritório, não valeria a pena até mesmo romper o vínculo com ela: "Acho que eu não me adaptaria a isso, depois de tanto tempo trabalhando em home-office” (E4).

Apenas o entrevistado E13 - solteiro e o mais jovem de todos - considerou mais vantajoso trabalhar na sede da empresa. Como motivos, mais uma vez é destacada a questão da visibilidade, além da dificuldade de se estabelecer limites para o tempo dedicado ao trabalho. Para ele, o trabalho no escritório permite "ter uma jornada de trabalho mais regular e, consequentemente, você poder se programar e se organizar melhor" (E13).

Há, ainda, quem considere que o ideal seria a combinação dos dois mundos - usufruir as vantagens do teletrabalho, mas podendo manter um grau de presença física no escritório: "Poder estar em contato com a 
empresa nos momentos necessários [...]. Porque os dois trabalhos são interessantes. Acho que sempre tem que ter um escritório por perto" (E9).

Para alguns, a satisfação com o trabalho não é, na verdade, consequência de se trabalhar no escritório ou em casa, mas de se gostar daquilo que se faz ("porque, independente, de ser home-office ou não, o que interessa é o que você está fazendo" - E12).

A flexibilidade de horários é um dos aspectos percebidos como mais positivos pelos indivíduos, corroborando a visão de autores como Haddon (1998). A principal razão apontada é o sentimento de maior autonomia na organização do próprio trabalho e, consequentemente, também na organização do tempo dedicado à vida pessoal e à família. Ter a liberdade de escolha, sem estar sujeito a uma rotina preestabelecida, foi um dos maiores benefícios citados: "[o] mais gratificante é você ser o dono do seu tempo [...]. Você não precisa seguir uma rotina, [...] você [é] que cria essa rotina" (E3). Grande parte dessa ideia de liberdade diz respeito a poder utilizar horários de trabalho alternativos: "Eu posso alterar, eu posso trabalhar à noite e, naquele dia específico, não trabalhar de manhã" (E3); "Eu posso, no meio do dia, parar e depois continuar trabalhando até a hora que eu quiser" (E6).

Porém, conforme observam autores como Hartig, Kylin e Johanson (2007), Hilbrecht et al (2008), Mann, Varey e Button (2000), Marsh e Musson (2008) e Tietze (2005), essa flexibilidade parece ter também um alto custo para alguns indivíduos, pois faltam referências que ajudem a definir os limites entre tempo e espaço de trabalho e de vida pessoal:

O mais negativo é que eu trabalho mais. Eu acho que não me desligo do trabalho, estou sempre trabalhando. Parece que a Shell está dentro da minha casa, [...] que, a qualquer momento, eu posso ser acionada. [...] A barreira entre a minha casa e o trabalho não existe mais, ficou muito tênue. (E9)

Talvez, por isso, para os entrevistados, um dos principais desafios enfrentados por quem migra para o teletrabalho diz respeito à necessidade de ajustar a disciplina de trabalho e de vida pessoal. Corroborando a visão de Tietze (2005), a maioria aponta que, após a migração, passou a ter mais liberdade para organizar suas atividades, mas que isso também exigiu maior responsabilidade e autocontrole. Um dos motivos, conforme discutido anteriormente, é a necessidade de garantir maior visibilidade: "para mostrar serviço, mostrar que você está fazendo, e tornar isso visível à distância para o seu supervisor e para a companhia” (E4). A disciplina é importante, ainda, para que se evite trabalhar em excesso e para não deixar as demandas dos familiares interferirem indevidamente na execução das tarefas (não é porque você está em casa que você está descansando, à disposição deles - E7). Mais do que um desafio, a disciplina é vista como um requisito para o sucesso do teletrabalhador, pois é fácil perder o controle de própria rotina, diante das múltiplas demandas e responsabilidades.

Essa necessidade de maior disciplina é algo gerado não necessariamente por demandas explícitas da organização, já que as cobranças são por resultados e cabe ao próprio teletrabalhador organizar a sua rotina. Ocorrem cobranças explícitas quando, por exemplo, alguém da empresa envia um e-mail e espera pronta resposta, obrigando o indivíduo a reorganizar as suas prioridades. Alguns mencionam, por exemplo, a percepção de que, em troca da maior autonomia, a empresa também eleva o nível de cobrança: "Não tem dúvida que a pressão aumentou e que eles imaginam que, por você também ter essa liberdade toda de horário, você pode trabalhar até mais tarde [...], eles esperam mais de você" (E8). Entretanto, as cobranças parecem ser muitas vezes autoimpostas, em função do sentimento de que o próprio indivíduo é o principal responsável pelos seus resultados:

Você não desliga. Por mais que você esteja parado, você sabe que o notebook está ali [...]. Por exemplo, no domingo, agora, eu trabalhei quase meio período, porque estava com alguns trabalhos atrasados e fui lá fazer. Porque eu não aguentei ver o notebook lá parado, e tudo dependia de mim. (E6) 
Há, ainda, as muitas distrações que decorrem do fato de se ter um escritório de trabalho tão próximo da vida doméstica e das possibilidades de lazer. A família parece funcionar, ao mesmo tempo, como fonte de distração e como um balizador de prioridades. Alguns relatos, como o exposto a seguir, sugerem que, aos poucos, os indivíduos vão aprendendo a negociar com a família os limites de tempo que devem dedicar ao trabalho no ambiente de casa:

Inicialmente, eu percebi que eu me tornei um workaholic, porque eu começava a trabalhar sete horas da manhã, e trabalhava até 10 horas da noite. Isso aconteceu nos primeiros seis meses. Depois, até em conversas com a minha esposa, eu percebi que eu tinha que ajustar isso. (E4).

Na medida em que passam a conviver, simultaneamente, com os dilemas e com as oportunidades decorrentes da condição de teletrabalhadores, os indivíduos vão aprendendo a encontrar um caminho para melhor equilibrar o trabalho com a vida pessoal:

Eu descobri que, um belo dia, o meu note foi roubado, e a Shell não acabou porque eu deixei de trabalhar uma noite. Você começa a pensar: "Poxa, eu tenho que me dedicar também ao filho" [...]. Então, eu me policio: acordo cedo, 8, legal, bacana, até às 6 [...]. Isso é acordado com o meu chefe. (E11)

\section{Consequênclas para a vida pessoal e para as relações socials e em famílla}

Conforme apontado anteriormente, a redução de custos corporativos é vista como um dos maiores ganhos da empresa. Porém, tal como observado por Mann, Varey e Button (2000), não necessariamente esse é um benefício também do teletrabalhador. Por um lado, há economias importantes, principalmente, nos custos com deslocamento, combustíveis, manutenção de veículos e vestuário. Esse último item parece ser mais percebido como vantagem pelas mulheres ("porque você pode trabalhar um pouco mais simples em casa; não tem que ter toda a preocupação de estar bem vestida" - E9), revelando, talvez, uma diferença de gênero. Por outro lado, essa economia parece ser atenuada pela elevação de outros tipos de despesas, tais como as de consumo doméstico (exemplos: eletricidade, água e telefone) ou decorrentes de novos hábitos de consumo ("o que eu economizo de gasolina eu acabo gastando mais por estar na rua, um almoço ou numa compra por impulso" E8). Há também queixas de que o valor mensal fornecido para cobrir a elevação das despesas domésticas não foi atualizado desde a criação do programa, nem leva em conta os diferentes contextos: "em uma cidade como o Rio de Janeiro, com temperaturas altas, você estando em casa, você gasta mais; você abre a geladeira mais, usa o ar-condicionado, ventilador de teto..." (E5).

Sobre a questão do deslocamento, alguns entrevistados mencionaram que as vantagens do teletrabalho não estariam associadas somente à redução de custos, mas também a outros fatores, como, por exemplo, a liberação do estresse de enfrentar o trânsito da cidade:

Em São Paulo, eu demoro uma hora para chegar, mais uma hora para voltar. De repente, para almoçar é mais meia hora, 45 minutos. Então, é uma média de três horas por dia que eu ganho, fora o estresse do trânsito. (E9)

Menos deslocamento também significa menos exposição à violência urbana. Apesar de citado por apenas um entrevistado, esse talvez seja um benefício para os que vivem em muitas cidades brasileiras: "eu não preciso me preocupar se vou voltar tarde para casa" (E8).

Uma das principais vantagens mencionadas pelos entrevistados é o ganho de qualidade de vida que o teletrabalho parece proporcionar. Há, por exemplo, a possibilidade de planejar melhor as múltiplas prioridades da vida: "me dedicar às aulas de inglês com mais tranquilidade, adequar o meu horário a isso, me dedicar a uma atividade" (E5). Há ainda a praticidade de resolver problemas pessoais sem estresse adicional e sem afetar a produtividade: "ir ao banco, ao Detran [...]. Se você estivesse trabalhando em um escritório, em horário fixo, você teria que usar o seu horário de almoço ou faltar ao emprego" (E7). Contudo, uma das principais razões, 
citada principalmente pelos que são casados e têm filhos, tanto homens quanto mulheres, tal como observado por Hilbrecht et al (2008), é a possibilidade de dispor de mais tempo com a família:

Qualidade de vida de poder estar até às nove horas em casa com meu filho, ver ele acordar e me falar tchau e voltar lá às cinco horas e ele estar lá acordado, brincar um pouquinho com ele [...] e depois voltar a trabalhar tranquilo [...]. Para a minha esposa, foi um grande benefício, porque eu ainda posso ajudar em algumas coisas que, teoricamente, ela sozinha em casa não poderia fazer. (E2)

Porém, essa disponibilidade não é total e nem sempre a família entende que há fronteiras que precisam ser criadas entre o trabalho e a vida doméstica ("As pessoas precisam ser, de certa forma, educadas, doutrinadas; entenderem que você está trabalhando" - E9). O maior problema parece ser compatibilizar as diferentes prioridades:

Eu tenho uma filha de quase nove anos e um de quatro anos e meio. A maior, 70, 80\% dos momentos em que eu estou em casa, ela compreende que eu estou trabalhando e respeita isso. Mas há momentos em que ela esquece e efetivamente me atrapalha. O menor já é o inverso; 70, 80\% dos momentos, ele me atrapalha, efetivamente, porque ele quer ir lá, ele quer brincar, ele quer conversar, ele quer entender. E minha esposa, ela entende que eu estou trabalhando até o momento que ela chega em casa do trabalho. Quando ela chega [...], entende que eu tenho que parar para ficar com as crianças, para que ela possa descansar. (E4)

Entre os entrevistados, havia apenas uma mulher casada e com filho. No entanto, seu discurso sugere que, para as mulheres, é maior a necessidade de conciliação, pois o envolvimento com o cuidado das crianças tende a ser maior (HADDON, 1998; HARTIG; KYLIN, C.; JOHANSON, 2007; HILBRECHT et al, 2007; OSNOWITZ, 2005). No caso dessa entrevistada, a saída encontrada foi contratar uma babá, uma solução que, entretanto, revelou-se parcial: "qualquer problema em que ela tenha dificuldade, ela vai lá e te interrompe". Ainda assim, os benefícios de estar perto da criança superam as dificuldades: "porque eu estou do lado e estou vendo o que está acontecendo" (E11).

Tietze (2005) observou que alguns indivíduos tentam delimitar o tempo dedicado ao trabalho e à vida doméstica por meio de artefatos visíveis, tais como o dress code. Esse foi um recurso até mesmo recomendado pela Shell Brasil, quando implantou o teletrabalho, como forma de disciplinar a convivência com a família e lembrar ao teletrabalhador a sua real condição. Somente o entrevistado E7 fez menção, no entanto, ao emprego desse recurso.

A maioria dos entrevistados não possui uma área da casa dedicada exclusivamente para o trabalho. A verba de R \$750 concedida pela empresa quando da migração, foi, em geral, utilizada para adquirir mobiliário e para realizar pequenos ajustes no espaço doméstico. Contudo, ela não solucionou problemas de espaço reduzido. Mesmo os que possuem um cômodo prioritariamente usado como escritório, precisam, às vezes, compartilhá-lo com outros familiares ou não conseguem mantê-lo isolado da agitação da casa. Para os que não têm esse tipo de espaço reservado, a dificuldade de criar limites parece ser ainda maior:

Uma coisa que realmente não tem como resolver é a questão de eu trabalhar no meio da minha sala e eu ter os meus filhos, principalmente, no periodo da manhã [...], estar ao telefone conversando [...] com o meu supervisor, com clientes [...] e, poxa, é cachorro latindo, é filho berrando, querendo conversar. (E4)

O grau de dificuldade de compartilhar espaço depende do tamanho da família e da residência, bem como do estilo de vida dos familiares e do relacionamento entre eles. O entrevistado E5, por exemplo, tem filhos adolescentes que se ocupam de várias atividades fora de casa, reduzindo assim os problemas. Já os que têm filhos pequenos, têm menos alternativas para driblar as dificuldades.

Essas preocupações com a delimitação de espaço entre o trabalho e a rotina da casa não se devem apenas às interferências da família sobre o desempenho das tarefas, mas também ao inverso, ou seja, à inevitável exposição da família aos problemas da empresa: 
Um dia, [...] nós tivemos um problema sério de distribuição no Brasil. Cara, eu acordei às sete horas da manhã, liguei o celular e o celular começou a tocar. Eu parei de falar no celular às duas horas da tarde. Eu estava de pijama e não tinha tomado o meu café da manhã [...]. Você imagina a satisfação da minha família de estar acompanhando esse processo comigo. (E14)

Apesar da dificuldade de adaptar a rotina doméstica para receber o "local de trabalho", o sentimento dominante é o de que os familiares e as pessoas mais próximas já conseguem entender melhor a complexidade da vida do teletrabalhador. No entanto, o mesmo não parece acontecer com as pessoas que não participam desse círculo mais íntimo. Algumas pessoas parecem não entender que trabalhar em casa não significa trabalhar menos. A primeira reação tende a ser a visão do teletrabalhador como um privilegiado: "que boa vida, que inveja que eu tenho... você está ai trabalhando de bermuda e camiseta..." (E10). Mesmo quando não revelam uma ideia preconcebida, as pessoas tendem a se mostrar curiosas: " $E$ aí, como funciona? Você trabalha mesmo? [...]'. O pessoal fica sempre curioso pra saber. Não sabem a demanda que é” (E9). Parece haver uma forte mitificação do teletrabalhador; principalmente, por quem teve menos possibilidades de conviver com essa realidade:

As pessoas mais jovens sabem que, pelo ritmo de trabalho, hoje, você não consegue desenvolver nenhuma função trabalhando pouco. Mas as pessoas mais velhas imaginam que você é dono da companhia. (E8)

Apesar de alguns indivíduos afirmarem não se importar com essa visão distorcida, a frequência com que tais depoimentos surgiram revela que o incômodo existe, possivelmente, afetando sua identidade e autoestima, como observa Perin (1998). Um depoimento fornece uma "pista" de que, no caso das mulheres, o preconceito pode ser maior:

Até hoje, em meu condomínio, os porteiros não entendem o que eu faço [...]. Eles pensam que eu fico em casa, que só o pobre do [marido] trabalha [...]. Quando você desce e conversa com algumas mães, diz "não, eu trabalho em casa" [...], já pensam assim em alguma coisa manual, artesanal, nada corporativo. (E11)

\section{Discussão dos resultados}

Analisando o caso dos funcionários teletrabalhadores da Shell Brasil, pela configuração do home-office, este estudo teve o objetivo principal de levantar os tipos de consequências que os indivíduos percebem que a atuação nessa modalidade de trabalho traz para as suas vidas profissional e pessoal.

Observa-se, em primeiro lugar, que, tal como verificado por outros autores como Costa $(2004 ; 2007)$, Silva (2008), Tietze (2005), Tombari e Spinks (1999) e White et al (2003), os indivíduos são capazes de mencionar, espontaneamente, tanto consequências positivas quanto custos pessoais associados às suas experiências de realização do trabalho em casa, o que mostra o grau de complexidade do tema. De qualquer forma, percebeu-se no discurso da maioria dos entrevistados um nível aparentemente elevado de adesão a essa forma de trabalho, sugerindo assim que, segundo o ponto de vista predominante, os benefícios superam os custos. Tal como apontado pela literatura especializada, alguns dos benefícios que mais se destacaram no "pacote" de vantagens percebidas são: a maior autonomia para organizar o trabalho, a flexibilidade para gerir o próprio tempo e o sentimento de maior qualidade de vida, principalmente, quando essa qualidade de vida inclui a melhoria das relações em família. Também coincidindo com o que é mencionado na literatura de referência, o "pacote" das desvantagens inclui, especialmente, as dificuldades de manter a visibilidade profissional, de estabelecer limites para a autocobrança e de conciliar o trabalho com a vida doméstica.

A análise das falas dos indivíduos permitiu, porém, a identificação de três categorias principais, que parecem representar elementos balizadores das percepções dos indivíduos acerca de sua condição: as consequências que ela traz para o seu desempenho profissional e para as suas expectativas sobre a relação de trabalho com a empresa; as consequências para a sua relação com o trabalho; e as consequências para a sua vida pessoal e para as suas relações sociais e em família. 
Essa diversidade de critérios sugere que os indivíduos tendem a desenvolver um olhar mais integral sobre tais consequências, no qual as questões relativas à vida pessoal e à profissional parecem assumir pesos significativos, embora as percepções mais positivas tenham sido geralmente associadas à dimensão pessoal e familiar. No discurso da maioria dos entrevistados, parece haver certa resignação de que pode haver custos para a carreira na empresa. No entanto, esses custos parecem ser compensados pela percepção de que o desempenho de suas tarefas não tem sido significativamente prejudicado, de que o trabalho no escritório também oferece inconvenientes dos quais se sentem até certo ponto liberados e, principalmente, de que conseguem gerir melhor os dilemas decorrentes da necessidade de equilibrar o trabalho e a vida pessoal.

De qualquer modo, chama a atenção o discurso do entrevistado mais jovem. Talvez, por ser solteiro e sem filhos, foi o único a dizer que preferia voltar a trabalhar no escritório, o que mostra que nem sempre a balança das prioridades dos indivíduos pende mais para o lado da vida pessoal do que para os das expectativas profissionais. Além disso, mesmo os demais demonstraram claramente não esquecerem o fato de que, mesmo trabalhando em casa, estão inseridos, como empregados, em um contexto corporativo ao qual precisam estar integrados. Um dos principais desafios que enfrentam é justamente o de estabelecer essa integração, sem que os dois ambientes de inserção, o da empresa e o de casa, criem dificuldades, um para o outro. Nesse sentido, o seu discurso mescla dois tipos de percepção. A primeira é a de que são, em grande parte, responsáveis pelo seu próprio sucesso como teletrabalhadores, na medida em que cabe a eles ter autodisciplina e negociar com os familiares para que possam melhor desempenhar os seus papéis como profissionais, pais, mães, maridos e esposas. A segunda é a de que continuam sendo empregados e, por isso, dependem de que as interfaces com seus pares, supervisores e clientes funcionem adequadamente. Além disso, sabem que têm de apresentar os resultados esperados pela empresa, a qual, consequentemente, deve expor-lhes as regras do jogo, garantir-lhes as condições materiais de que necessitam e ser capaz de reconhecer seu esforço e desempenho.

No entanto, é preciso ressaltar também que a maioria dos entrevistados migrou para a condição de home-office após ter atuado por um período nos escritórios da empresa. É possível que as bases que delineiam essa relação entre os indivíduos e a empresa venham a ser vistas de modo diferente, na medida em que alguns indivíduos passam a ser admitidos já atuando nesse tipo de configuração. Cabe lembrar, ainda, que, apesar de, em sua maioria, mostrarem-se satisfeitos com a forma de atuação corrente, os indivíduos têm consciência de que, a qualquer momento, a empresa pode requisitá-los de volta ao escritório. Nessa situação, como revela o discurso do entrevistado E4, ser "empregado" e "teletrabalhador" pode deixar de ser uma característica combinada para se tornar uma escolha entre duas alternativas de vida.

O discurso dos indivíduos também permitiu identificar um elenco de aspectos que parecem influir, positiva ou negativamente, na sua adaptação ao trabalho realizado de casa e nas suas percepções de vantagens e custos associados. Alguns dos aspectos mais destacados nos discursos dos entrevistados dizem respeito a: características pessoais, como, por exemplo, a capacidade de autodisciplina; características da empresa, como a política relativa ao teletrabalho, a comunicação e a facilidade de acesso aos pares e superiores; recursos e procedimentos disponibilizados pela empresa para que os indivíduos possam realizar seu trabalho em casa; características do trabalho em si, como a natureza das tarefas e o nível de interdependência com as outras pessoas da empresa e com os clientes; características da família, tais como o número de pessoas e a idade dos filhos; ambiente doméstico, envolvendo a existência de espaço apropriado para o trabalho e se este é compartilhado com outros membros da família; infraestrutura da sociedade, envolvendo aspectos como a dificuldade de deslocamento e a segurança urbana.

Muitos desses elementos condicionantes coincidem com aqueles apontados mais genericamente na literatura por autores como Felstead, Jewson e Walters (2003), Fulton (2002), Mann, Varey e Button (2000), Marsh e Musson (2008), McGrath e Houlihan (1998), Mitchell (1996), Tietze (2005) e Ward e Shabha (2001). Outros talvez sejam mais associados ao contexto específico do grupo de teletrabalhadores entrevistados.

É possível, por exemplo, que a percepção mais positiva revelada pelos entrevistados, acerca de sua condição atual, seja reforçada pelo fato de que essa modalidade de teletrabalho é parte do discurso estratégico de recursos humanos da empresa, o que, de certa forma, pode lhes garantir um nível maior de segurança quanto aos riscos de continuidade da sua relação de trabalho. Contribui para isso o fato de que eles percebem que a empresa 
também consegue extrair benefícios dessa política. Além disso, eles entendem que as condições oferecidas pela empresa, se não são ideais, pelo menos, ajudaram a reduzir as dificuldades que eles poderiam enfrentar.

Outros aspectos que parecem refletir uma realidade mais específica do grupo de entrevistados são o fato de considerarem vantajoso não ter de enfrentar diariamente o intenso trânsito urbano e a preocupação com a segurança quando eventualmente precisam se deslocar com seus equipamentos. Nesse sentido, cabe lembrar que a maior parte dos entrevistados reside nas duas maiores metrópoles brasileiras, onde tais problemas são relevantes.

Essas observações, portanto, permitiram compor um quadro conceitual representativo dos aspectos que parecem influenciar a percepção dos empregados teletrabalhadores da Shell Brasil acerca das vantagens e desvantagens de atuar no regime home-office, apresentado na figura 1. Cabe ressaltar, porém, que não se trata da proposição de um "modelo preditivo" do comportamento dos indivíduos, mas sim da tentativa de representação visual da lógica discursiva revelada pelos entrevistados, em suas avaliações sobre as consequências de sua atuação nessa modalidade de trabalho na empresa.

Figura 1 - Aspectos que influenciaram a percepção dos indivíduos acerca das vantagens e desvantagens de sua atuação como trabalhadores no regime home-office na Shell Brasil

ELEMENTOS CONDICIONANTES

- Características pessoais (ex. capacidade de autodisciplina)

- Características da empresa (ex: política relativa ao teletrabalho, a comunicação e a facilidade de acesso aos pares e superiores)

- Recursos e procedimentos disponibilizados pela empresa para o trabalho em casa

- Características do trabalho em si (ex: natureza das tarefas e o nível de interdependência com as outras pessoas da empresa e com os clientes)

- Características da família (ex: número de pessoas e idade dos filhos)

- Características do espaço doméstico (ex: tamanho da residência, existência de espaço apropriado para o trabalho e se ele é compartilhado com outros membros )

- Infra-estrutura da sociedade (ex: dificuldade de deslocamento e a segurança urbana)
ELEMENTOS

BALIZADORES

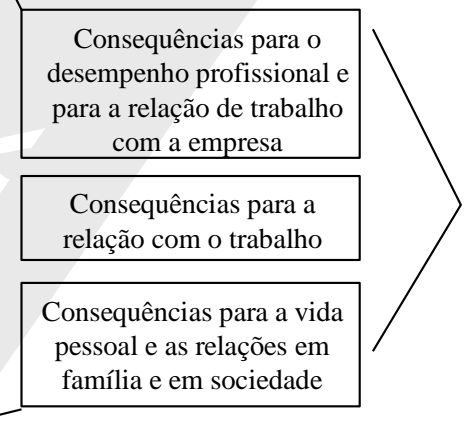

Percepção

sobre as

vantagens e

desvantagens

da condição

de

empregado

home-office

Fonte: elaborada pelos autores.

\section{Considerações finals}

Os resultados deste estudo não preenchem todas as lacunas de conhecimento sobre o teletrabalho. Isso ocorre, principalmente, por se tratar de uma pesquisa descritiva (VERGARA, 1997) que aborda um tipo de configuração específica e por esse ser um assunto em que as experiências são novas, tanto para as empresas quanto para os indivíduos. No entanto, esses resultados trazem uma contribuição relevante para o crescente debate sobre o tema. Por envolver uma das primeiras organizações a adotar esse tipo de programa no país e considerando o bom nível de adaptação ao teletrabalho dos entrevistados, o caso Shell Brasil é revelador dos diferentes aspectos que podem influenciar a percepção dos indivíduos sobre sua própria condição e, provavelmente, sobre seu sucesso e satisfação.

A experiência dos teletrabalhadores da Shell Brasil, embora única, pode servir de inspiração para que outras organizações que planejam implementar alternativas similares de trabalho identifiquem potenciais dificuldades experimentadas por seus empregados, criando condições que minimizem tais dificuldades ou facilitem a adaptação desses profissionais a essa nova modalidade de trabalho. Os resultados deste estudo sugerem que tais condições não estão relacionadas somente à definição de responsabilidades e procedimentos e à disponibilização de recursos de apoio. A realidade de vida de cada profissional é única e requer uma avaliação personalizada, da qual é importante que o próprio indivíduo participe ativamente, em uma negociação que envolva também seus familiares. Também para os indivíduos que migram para esse tipo de configuração de 
trabalho - seja como empregados em uma empresa, seja como autônomos -, os resultados deste estudo podem fornecer uma referência interessante sobre alguns aspectos a serem levados em conta em seu planejamento de vida.

Futuros estudos podem contribuir para ampliar essa discussão, analisando casos de empregados teletrabalhadores de outras empresas que atuem em outros tipos de configuração, como por exemplo, os nômades ou móbile teleworkers (GARRETT; DANZIGER, 2007). Podem ainda abarcar outros perfis de indivíduos, como os autônomos ou os portadores de deficiência, para quem o teletrabalho pode trazer maiores chances de inserção no mercado. Tal como sugerido por Golden (2007), é igualmente interessante que, em relação a empresas como a Shell Brasil, que mantêm múltiplas formas de configuração do trabalho, outros estudos possam comparar as percepções dos teletrabalhadores com as dos profissionais que continuam atuando nos escritórios.

Algumas questões tangenciadas neste estudo, como as referentes a gênero, natureza da atividade profissional, tempo de experiência profissional do indivíduo e efeitos do trabalho na configuração da sua identidade e subjetividade, também podem ser aprofundadas futuramente. Particularmente no que tange à questão do gênero, a exemplo dos resultados encontrados por Marsh e Musson (2008), alguns indivíduos do sexo masculino - em maioria nesta pesquisa - defenderam o equilíbrio entre os papéis de pai e profissional, num discurso muito próximo daquele tradicionalmente associado às mulheres. Tal como levantado por aquelas autoras, isso poder sinalizar uma mudança mais profunda, ainda inicial, que estaria se operando na estrutura das famílias que vivenciam esse tipo de experiência. Quanto às questões relativas à identidade dos indivíduos, estas aparecem no discurso dos entrevistados quando estes, por exemplo, reclamam de não se sentirem vistos por seus interlocutores organizacionais - em alguns casos, até pelos vizinhos - como ativos e produtivos. Como já observado, essas questões podem ser aprofundadas por outros estudos, como os de Brocklehurst (2001) e de Marsh e Musson (2008).

Finalmente, também a exemplo do que fora verificado por Costa (2007), grande parte do que os indivíduos entendem como vantagens do teletrabalho parece estar relacionada a uma maior autonomia, ao "empreendedorismo de si" (Ibidem, p.122) ou à possibilidade de afirmação de sua subjetividade. Essa é outra questão sobre a qual há muito a ser explorado e que também foi apenas circunstancialmente tangenciada neste estudo. 


\section{Referênclas}

BENTLEY K. YOONG P. Knowledge work and telework: an exploratory study. Internet Research: Electronic Networking Applications and Policy, v.10, n.4, P.346-356, 2000.

BOLTANSKI, L. CHIAPELLO, E. Le nouvel esprit du capitalisme. Paris: Gallimard, 1999.

BROCKLEHURST, M. Power, identity and new technology homework: implications for "new forms" of organizing. Organization Studies, v.22, n.3, p.445-456, 2001.

BÜSSING, A. Teleworking and quality of life. In: JACKSON, P. F.; VAN DER WIELEN, J. M. (Org.). Teleworking: international perspectives from telecommuting to the virtual organization. London: Routledge, 1998. p.144-165.

CAPPELLI, P. The New Deal at work. Boston: Harvard Business School Press, 1999.

COSTA, I. S. A. Poder/saber e subjetividade na construção do sentido do teletrabalho. 2004. 124f. Tese (Doutorado em Administração) - Escola Brasileira de Administração Pública e de Empresas, Fundação Getúlio Vargas, Rio de Janeiro, 2004.

Teletrabalho: subjugação e construção de subjetividades. Revista de Administração Pública, v.41, n.1, p.105-124, 2007.

CRESWELL, J. W. Qualitative inquiry and research design: choosing among five traditions. California: Sage, 1997.

DEWETT, T.; JONES, G. R. The role of information technology in the organization: a review, model and assessment. Journal of Management, v.27, p.313-346, 2000.

FELSTEAD, A.; JEWSON, N.; WALTERS, S. Managerial control of employees working at home. British Journal of Industrial Relations, v.4, n.1-2, p.241-264, 2003.

FULTON, C. Information control in the virtual office: preparing intermediaries to facilitate information exchange in the home work environment. New Library World, v.103, n.6, 2002.

GARRETT, R. K.; DANZIGER, J. N. Which telework? Defining and testing a taxonomy of technology mediated work at a distance. Social Science Computer Review, v.25, n.1, p.27-47, 2007.

GOLDEN, T. D. Co-workers who telework and the impact on those in the office: understanding the implications of virtual work for coworker satisfaction and turnover intentions. Human Relations, v.6o, n.11, p.1641-1667, 2007.

VEIGA, J. F. The impact of extent of telecommuting on job satisfaction: resolving inconsistent findings. Journal of Management, v.31, n.2, p.301-318, 2005.

HADDON, L. The experience of teleworking. In: JACKSON, P. F.; VAN DER WIELEN, J. M. (Org.). Teleworking: international perspectives from telecommuting to the virtual organization. London: Routledge, 1998. p.136-143.

HARTIG, T.; KYLIN, C.; JOHANSON, G. The telework tradeoff: stress mitigation vs. constrained restoration. Applied Psychology: an International Review, V.56, n.2, p.231-253, 2007.

HILBRECHT, M. et al. 'I'm home for the kids': contradictory implications for work-life balance of teleworking mothers. Gender, Work and Organization, v.15, n.5, p.454-476, 2008.

HISLOP, D.; AXTELL, C. The neglect of spatial mobility in contemporary studies of work: the case of telework. New Technology, Work and Employment, v.22, n.1, p.34-51, 2007.

KUMAR, K. Da sociedade pós-industrial à pós-moderna. Novas teorias sobre o mundo contemporâneo. Rio de Janeiro: Jorge Zahar, 1997.

MANN, S.; VAREY, R.; BUTTON, W. An exploration of the emotional impact of teleworking via computer-mediated communication. Journal of Managerial Psychology, V.15, n.7, 2000.

MARSH, K.; MUSSON, G. Men at work and at home: managing emotion in telework. Gender, Work and Organization, v.15, n.1, p.3148, 2008.

MARTÍNEZ-SÁNCHEZ, A. et al. Telework, human resource flexibility and firm performance. New Technology, Work and Employment, v.22, n.3, p.208-223, 2007.

MCGRATH P., HOULIHAN, M. Conceptualising telework: modern or postmodern? In: JACKSON, P. F.; VAN DER WIELEN, J. M. (Org.). Teleworking: international perspectives from telecommuting to the virtual organization. London: Routledge, 1998. p.56-59.

MITCHELL, H. The social implications of telework: the UK experience. World Transport Policy \& Practice, v.2, n.1-2, p.29-35, 1996. 
MORGAN, R. Teleworking: an assessment of the benefits and challenges. European Business Review, v.16, n.4, p.344-357, 2004. NILLES, J. M. What does telework really do to us? World Transport Policy \& Practice, v.2, n.1-2, p.15-23, 1996.

OSNOWITZ, D. Managing time in domestic space: home-based contractors and household work. Gender \& Society, v.19, n.1, p.83103, 2005.

PAPALEXANDRIS, N.; KRAMAR, R. Flexible working patterns: towards reconciliation of family and work. Employee Relations, v.19, n.6, p.581-595, 1997.

PATRICKSON, M. Teleworking: potential employment opportunity for older workers? International Journal of Manpower, v.23, n.8, p.704-715, 2002.

PERIN, C. Work, space and time on the threshold of a new century. In: JACKSON, P. F.; VAN DER WIELEN, J. M. (Org.). Teleworking: international perspectives from telecommuting to the virtual organization. London: Routledge, 1998, p.40-55.

QVORTRUP, L. From teleworking to networking: definitions and trends. In: JACKSON, P. F.; VAN DER WIELEN, J. M. (Org.). Teleworking: international perspectives from telecommuting to the virtual organization. London: Routledge, 1998. p.21-27.

ROUSSEAU, D. M. Contracting: a modern dilemma. Psychological contracts in organizations. Thousand Oaks: Sage, 1995.

SILVA, J. R. G. Profissionais qualificados e experiência de autoemprego: questões de tempo e espaço. REAd, v.14, n.1, 2008.

WETZEL, U. A construção de um quadro analítico sobre as significações de espaço no contexto das mudanças organizacionais. Cadernos Ebape.BR., v.5, n.4, p.1-16, 2007 .

Organizational change and the meaning of time. BAR-Brazilian Administration Review, v.4, p.16-30, $2007 \mathrm{~b}$.

SOBRATT - Sociedade Brasileira de Teletrabalho. Disponível em: <www.sobrat.org.br>. Acesso em: 10 mar. 2007.

TOMBARI, N.; SPINKS, N. The work/family interface at Royal Bank Financial Group: successful solutions - a retrospective look at lessons learned. Women in Management Review, v.14, n.5, p.186-193, 1999.

TREMBLAY, D. Balancing work and family with telework? Organizational issues and challenges for women and managers. Women in Management Review, v.17, n.3-4, 2002.

TIETZE, S. Discourse as strategic coping resource: managing the interface between "home" and "work". Journal of Organization change management, v.18, n.1, p.48-62, 2005.

2002.

When "work" comes "home". Copying strategies o teleworkers and their families. Journal of Business Ethics, v.41, p.385-396,

VERGARA, S. C. Relatórios de pesquisa em administração. São Paulo: Atlas, 1997.

VIEIRA, M. Sobre a dimensão tempo-espaço na análise organizacional, RAE-Revista de Administração de Empresas, v.9, n.2, p.103-119, 2005 .

WARD, N. SHABHA, G. Teleworking: an assessment of socio-psychological factors. Facilities, v.19, n.1-2, p. 61-70, 2001.

WHITE, M. et al. 'High performance' management practices, working hours and work-life balance. British Journal of Industrial Relations, v.41, n.2, p.175-195, 2003.

WILKS, L.; BILLSBERRY, J. Should we do away with teleworking? An examination of whether teleworking can be defined in the new world of work. New Technology, Work and Employment, v.22, n.2, p.168-177, 2007. 